\title{
MODELLING OF TIME, COST AND RISK OF CONSTRUCTION WITH USING FUZZY LOGIC
}

\author{
Edyta PLEBANKIEWICZ $\mathbb{D}^{*}$, Krzysztof ZIMA®, \\ Damian WIECZOREK (D)
}

Faculty of Civil Engineering, Cracow University of Technology, Cracow, Poland

Received 12 November 2020; accepted 27 January 2021

\begin{abstract}
The paper presents an overview of the literature from recent years devoted to planning the time, costs and risk of a construction investment using fuzzy logic. It also presents three own original models concerning the issue. The first model is used to build a fuzzy construction schedule taking into account fuzzy norms and the number of workers. The costing model uses fuzzy inference from CBR cases. The aim was to increase the accuracy and correctness of the cost calculation performed for the investor in the construction and investment process with a certain degree of vagueness of the available information about materials. In the last of the presented models, fuzzy sets were used to assess the effects of technological and construction (implementation) risk factors. The presented examples prove the usefulness of fuzzy logic in solving problems in construction, where we have incomplete and imprecise information.
\end{abstract}

Keywords: cost, time, risk, construction, fuzzy set, case based reasoning.

\section{Introduction}

The elements which are subject to special planning and control by both contracting authorities and contractors are the time and cost of investment execution. Given the level of risk and uncertainty associated with the precise determination of both time and cost of the construction project, this is an extremely difficult, complex and complicated task. Fuzzy logic is ideal for solving such complex problems where incomplete and imprecise information is used, and the assessment of the impact of factors to be taken into account is often non-quantifiable. Therefore, in order to solve problems related to establishing time and cost, as well as to assess the risks of construction investments, researchers very often use the fuzzy set theory.

The aim of the paper is to indicate the possibilities offered by the theory of fuzzy sets in decision making in construction in the broadest possible scope. In line with this objective, time and cost analyzes are shown with different examples to show the possibilities of use in different construction works. The first model involved building a schedule based on uncertain and imprecise data in the form of fuzzy norms, the number of works and the number of employees. The next example is a case based reasoning using the fuzzy number theory used to support cost calculation and named by the authors FCBR CSM (Fuzzy
Case Based Reasoning Cost Support Method). In the last of the proposed models, the authors used the mathematical foundations of the Mamdani fuzzy inference model to build a model of fuzzy assessment of risk factors.

The rest of the paper is structured as follows: Section 1 presents the literature review broken down into the use of fuzzy sets for time, cost and risk modelling in construction. In Sections 2, 3 and 4 the examples of models using fuzzy logic are included. Section 5 provides discussion of the results. Conclusions are drawn in the end of this study.

\section{Literature review}

\subsection{Time}

Both the ordering party and the contractor are interested in the proper planning of the construction project implementation time. The clients, especially in relation to commercial investments, want to know when they will be able to, for instance, rent the space of the building and make profits, compensating for the expenses invested in the implementation. The proper planning of the investment realization time also depends on the contractor's compliance with the contractual conditions. Planning the time of a construction project is a complex process. It is necessary

${ }^{\star}$ Corresponding author. E-mail: eplebank@L7.pk.edu.pl 
to know the technologies used and the related working time standards, which in turn are affected by various internal and external factors, often hard to predict. A classic example can be the changing weather conditions, on which the realization time may depend to a large extent. Planning the implementation time can be considered both in relation to the whole schedule setting the completion date and to individual factors influencing the calculated time. In both of these aspects fuzzy logic can be used.

The basic method used in scheduling is CPM (critical path method), which allows to determine the sequence of activities, the implementation of which is crucial to achieve the assumed date of investment completion. The information concerning the investment realization time is often difficult to determine unambiguously. Hence, many authors have attempted to analyze the critical path using fuzzy sets. Such attempts were made by, for instance, Chanas and Zielinski (2001), Chen and Hsueh (2008), Kumar and Kaur (2010), Shakeela and Gansean (2011) and Soltani and Haji (2007). However, few authors have presented analyses of fuzzy CMP on examples of specific construction projects. Such an example was presented by Han et al. (2006) who included an airport construction project in his research. Morovatdar et al. (2013) proposed an algorithm for the Fuzzy CPM using piecewise numbers. Elizabeth and Sujatha (2013) introduced new approaches to identify the fuzzy critical path in the form of ranking methods. The presented empirical examples prove the effectiveness of this method. Several publications consider resource-constrained project scheduling problems. Castro-Lacouture et al. (2009) proposed fuzzy mathematical models that allow the multiobjective optimization of project schedules considering constraints such as time, cost, and unexpected materials shortages. Khalilzadeh et al. (2017) described an algorithm for project scheduling with fuzzy time and resources. Bhaskar et al. (2011) propose a heuristic method for resource constrained project scheduling problem with fuzzy activity times. This method is based on priority rule for parallel schedule generation scheme. Ibadov (2019) presents a method combining elements of fuzzy set theory and probability theory that enables the direct determination of the probability of meeting the fuzzy time constraint. Plebankiewicz and Karcińska (2016) suggested scheduling methods basing on fuzzy values of working time norms and employee numbers. The proposed procedure allows for determining a real duration of a project taking into account various factors affecting durations of single activities. Pawan and Lorterapong (2016) present integrated framework for assessing time contingency in construction projects.

\subsection{Cost}

Construction investment costs are calculated at all stages of the investment process, from planning to final as-built analyses. The earlier the stage, the more general the data for analysis and the less precise the cost analysis itself.
Taking into account the frequent problem of data availability and the specificity of the investment process, which is influenced by a number of factors, the cost calculations are burdened with a high degree of uncertainty.

Fuzzy logic supports the calculation of costs at different stages of the investment process. The smallest amount of data and at the same time the highest uncertainty characterize the calculations at the initial stage of investment planning. For these reasons, Meharie et al. (2019) proposed a cost calculation methodology at this stage of the investment, using factor analysis and fuzzy AHP. The factor analysis is used to classify and reduce the input variables, fuzzy AHP based on the geometric mean method is employed to determine the weights of input variables. Latief et al. (2013) also proposed a preliminary cost estimation model, but this one used a regression analysis incorporated with adaptive neuro fuzzy inference system (ANFIS). Cheng et al. (2010) developed a Cost Estimates Using Evolutionary Fuzzy Hybrid Neural Network. Yu and Skibniewski (2010) prepared an integrating neurofuzzy system with conceptual cost estimation to discover cost related knowledge from residential construction projects.

A common phenomenon in the construction industry is cost overrun. A lot of research has been devoted to the factors influencing cost overrun as well as models allowing to determine the risk of its occurrence. Sharma and Goyal (2019) developed a fuzzy based model to estimate the risk magnitude of 55 important risk factors causing cost overrun in Indian construction projects. Models of cost overrun prediction based on the fuzzy logic were also developed by Knight and Fayek (2002), Dikmen et al. (2007), Phama et al. (2020), Amadi and Higham (2017), El-Maaty et al. (2017), Kim et al. (2018), Plebankiewicz (2018), Plebankiewicz and Wieczorek (2020), Islam et al. (2019).

The idea promoted, for example, by EU organisations is "life cycle thinking". It leads to the attempts to assess construction investments not only on the basis of implementation (investment) costs, but also of all the costs incurred during the entire life cycle of the building. The model allowing for estimating life cycle cost (LCC) was developed, for instance, by Plebankiewicz et al. (2019). Salah and Moselhi (2015) present a newly developed fuzzy-set based model for estimating, allocating, depleting, and managing contingency fund over the life cycle of construction projects. The focus of the study by Shaheen et al. (2007) is modelling cost range estimating using fuzzy set theory.

Time and cost problems are closely related in the construction process. Therefore, many authors analyze these issues together. Wang and Liang (2004) proposed the multiple fuzzy goals programming model to minimize project total costs, total completion time, and total crashing costs. San Cristobal (2013) proposed the use of the PROMETHEE method under fuzzy environments in order to determine the critical path of a network, considering not only time but also cost, quality and safety criteria. 


\subsection{Risk}

Problems of time and cost of construction projects are connected with uncertainty and risk in the construction investment process. Proper estimation of potential risks guarantees the achievement of the goals of the project (Ebrahimnejad et al., 2014). The analysis of time and cost in the context of their risk using fuzzy logic was undertaken by many authors. Zheng and $\mathrm{Ng}$ (2005) proposed methods based on fuzzy sets, to evaluate and manage risks in the underground construction projects. The proposed methodology used a fuzzy risk assessment approach to assess the priority of risks in terms of extra costs over the budget. A model of construction-project risk assessment was developed also by Zolfaghari and Mousavi (2018). Taylan et al. (2014) focused on the construction projects selection and risk evaluation by a hybrid model based on fuzzy analytic hierarchy process (AHP) and fuzzy technique for order of preference by similarity to ideal solution (TOPSIS). Abdelgawad and Fayek (2011) combined FMEA, fault tree, event tree and fuzzy logic result in a framework to risk management of construction projects. Zhang and Wei (2013) developed the concept of hesitant fuzzy sets (HFSs) to the MADM process to overcome uncertainty. They extended VIKOR and TOPSIS methods to the hesitant fuzzy data.

The risks taken into account in the life cycle cost calculation were analysed by Plebankiewicz and Wieczorek (2018), Plebankiewicz et al. (2020).

The occurrence of risk is influenced by many factors. As a multi-criteria problem using fuzzy logic, risk probability was analyzed, for example, by Zavadskas et al. (2016, 2018), Antucheviciene et al. (2015), Ghorabaee et al. (2018), Seker and Zavadskas (2017), Hashemi et al. (2016), Islam et al. (2017).

\section{Creating a construction schedule specifying fuzzy norms and the number of workers}

In the development of construction schedules, data is usually determined subjectively based on the knowledge and experience of the planner who prepares the schedule. The planner's knowledge, however, is approximate, and the hypotheses regarding the values of the input data for the preparation of the schedule are formulated imprecisely. The fuzzy sets theory enables modelling and processing of data difficult to quantify on the basis of probability theory and mathematical statistics.

The base of constructing a schedule is specifying the completion time. In the case of a schedule concerning the completion of a building the time can be calculated on the base of the standard work time for a given construction work, the amount of labour and the number of workers involved in the completion of the task are given, as follows:

$$
T_{i}=n_{i}^{*} L_{i} / r_{i},
$$

where $T_{i}$ indicates the time of work completion $i ; n_{i}$ - the standard (that is, the number of work units completed in a time unit); $L_{i}$ - the number of works; $r_{i}$ - the number of workers employed to complete the work $i$.

The article assumes that the construction project can be mapped on a one-point network of relations of one initial action $S$ indicating the beginning of construction with one final action $F$ meaning the completion of a construction. The analysis encompassed actions connected with relationships of the completion-beginning type, as in Figure 1.

In accordance with Eqn (1), the work completion times were established as shown in Table 1.

Table 2 presents the results of calculations of the earliest and the latest project completion deadlines, assuming that all values used are deterministically specified.

All components of the completion time are hard to specify unambiguously at the investment preparation and schedule building stage. The authors propose to define components of the time as fuzzy numbers. In principle, membership functions can be of different shape, but in practice, trapezoidal and triangular membership functions are most frequently used and, in many applications, turned out to be most efficient (Princy \& Dhenakaran, 2016).

Time standards can be found in various catalogues but they are adjusted to an average team of builders working in average conditions. The model proposed in the paper specifies the standard as a fuzzy number of the trapezoid

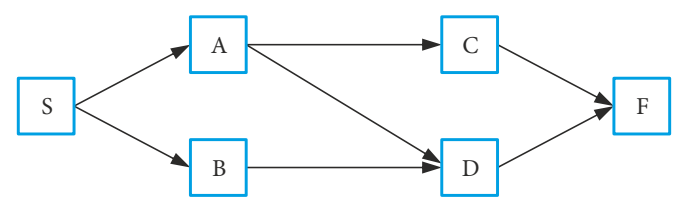

Figure 1. One-point network of relations used in the example

Table 1. Data in the relationship network according to Figure 1

\begin{tabular}{|c|c|c|c|c|}
\hline Work & Standard & $\begin{array}{c}\text { Number of } \\
\text { works }\end{array}$ & $\begin{array}{c}\text { Number of } \\
\text { workers }\end{array}$ & $\begin{array}{c}\text { Completion } \\
\text { time [days] }\end{array}$ \\
\hline A & $2.01 \mathrm{~m}-\mathrm{h} / \mathrm{m}^{3}$ & $100 \mathrm{~m}^{3}$ & 5 & 4 \\
\hline B & $3.40 \mathrm{~m}-\mathrm{h} / \mathrm{m}^{2}$ & $160 \mathrm{~m}^{2}$ & 5 & 11 \\
\hline C & $5.30 \mathrm{~m}-\mathrm{h} / \mathrm{m}^{3}$ & $45 \mathrm{~m}^{3}$ & 5 & 5 \\
\hline D & $0.24 \mathrm{~m}-\mathrm{h} / \mathrm{m}^{3}$ & $600 \mathrm{~m}^{3}$ & 5 & 3 \\
\hline
\end{tabular}

Table 2. The results of calculations of the earliest and the latest project completion deadlines

\begin{tabular}{|c|c|c|c|c|c|}
\hline \multirow[b]{2}{*}{ Work } & \multicolumn{2}{|c|}{ The earliest deadlines } & \multirow{2}{*}{$\begin{array}{l}\text { Re- } \\
\text { serve } \\
\text { time }\end{array}$} & \multicolumn{2}{|c|}{ The latest deadlines } \\
\hline & $\begin{array}{c}\text { of } \\
\text { beginning }\end{array}$ & $\begin{array}{c}\text { of } \\
\text { completion }\end{array}$ & & \begin{tabular}{|c|} 
of \\
beginning
\end{tabular} & $\begin{array}{c}\text { of } \\
\text { completion }\end{array}$ \\
\hline$S$ & 0 & 0 & 0 & 0 & 0 \\
\hline A & 0 & 4 & 5 & 5 & 9 \\
\hline $\mathrm{B}$ & 0 & 11 & 11 & 0 & 11 \\
\hline C & 4 & 9 & 5 & 9 & 14 \\
\hline $\mathrm{D}$ & 11 & 14 & 0 & 11 & 14 \\
\hline $\mathrm{F}$ & 14 & 14 & 0 & 14 & 14 \\
\hline
\end{tabular}


shape. The next component involves the amount of labour. Most frequently a schedule includes the amount of labour resulting from the cost calculation. The amount resulting from the project documentation does not always have the same value in reality. This is caused by a variety of factors, such as imprecise documentation, calculation errors, conditions different than those assumed, for instance, groundwater conditions in earth works, or changes added by the investor. Depending on the type of construction works, there exists a diverse risk of a change in the amount of works. The model proposed in the article employs the triangular membership function, as it is assumed that the value of the membership functions $=1$ is the value resulting from the cost calculation.

The number of construction workers is often treated as constant, although in reality it relies on many factors. Due to the variety of influences on the number of workers, the number may be specified in a non-deterministic way, using the fuzzy sets and fuzzy numbers theory. In the authors' opinion, the description of the number of construction workers factor is best illustrated by the trapezoidal membership function.

Assuming that the standard and the number of workers are fuzzy numbers with the trapezoid membership function, and the number of works is a fuzzy number with a triangular membership function, the following symbols will be used:

$$
\begin{aligned}
& N_{i}=\left(n_{i 1} ; n_{i 2} ; n_{i 3} ; n_{i 4}\right) ; \\
& L_{i}=\left(l_{i 1} ; l_{i 2} ; l_{i 2} ; l_{i 3}\right) ; \\
& R_{i}=\left(r_{i 1} ; r_{i 2} ; r_{i 3} ; r_{i 4}\right) .
\end{aligned}
$$

The product of the standard and the number of works can be calculated as follows:

$$
\begin{aligned}
& N_{i}{ }^{*} L_{i}=\left(n_{i 1} l_{i 1} ; n_{i 2} l_{i 2} ; n_{i 3} l_{i 2} ; n_{i 4} l_{i 3}\right)= \\
& \left(n l_{i 11} ; n l_{i 22} ; n l_{i 32} ; n l_{i 43}\right) .
\end{aligned}
$$

The time of construction completion can be calculated according to the Eqn (1):

$$
\begin{aligned}
& T_{i}=N_{i}{ }^{*} L_{i} / R_{i}=\left(n l_{i 11} / r_{i 4} ; n l_{i 22} / r_{i 3} ; n l_{i 32} / r_{i 2} ; n l_{i 43} / r_{i 1}\right)= \\
& \left(t_{i 1} ; t_{i 2} ; t_{i 3} ; t_{i 4}\right) .
\end{aligned}
$$

Table 3 presents data on construction works proceeding as in Figure 1, but with the assumption that the data are defined in a fuzzy form. This allows for the calculation of the execution time also in a fuzzy form.

Table 4 presents the results of calculations of the earliest and the latest fuzzy project completion deadlines.

Figure 2 shows a schedule based on deterministic values. Two versions of the schedule are included - one for the earliest and latest dates. Figures 3 and 4 contain schedules according to the earliest and latest dates but using fuzzy values.

The approach proposed by the authors allows for the development of a schedule in which the times of commencement and completion of individual tasks are fuzzy, and the order of execution of tasks is clearly determined and possible to implement at all possible times of completion.

The values of the fuzzy commencement and completion times are important information indicating the possibilities of various scenarios of investment completion times and individual works. Such information may be useful when there is a need to assess the degree of

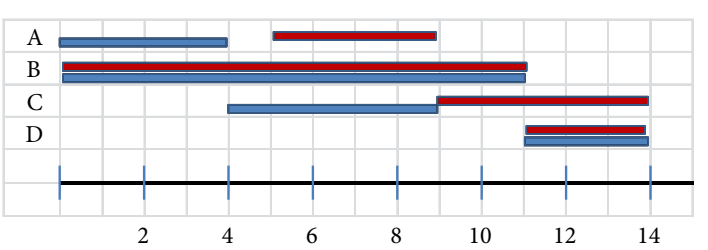

Figure 2. Schedule based on deterministic values

Table 3. Fuzzy data in the relationship network according to Figure 1

\begin{tabular}{|c|c|c|c|c|}
\hline Work & Standard & Number of works & Number of workers & Completion time [days] \\
\hline A & $(1.98 ; 2.01 ; 2.40 ; 2.50)\left(\mathrm{m}-\mathrm{h} / \mathrm{m}^{3}\right)$ & $(100 ; 150 ; 200) \mathrm{m}^{3}$ & $(4 ; 5 ; 6 ; 7)$ & $(5 ; 6 ; 6 ; 7)$ \\
\hline B & $(2.40 ; 3.40 ; 4.40 ; 4.90)\left(\mathrm{m}-\mathrm{h} / \mathrm{m}^{2}\right)$ & $(160 ; 190 ; 220) \mathrm{m}^{2}$ & $(4 ; 5 ; 6 ; 7)$ & $(10 ; 13 ; 14 ; 15)$ \\
\hline C & $(5.10 ; 5.30 ; 6.20 ; 6.30)\left(\mathrm{m}-\mathrm{h} / \mathrm{m}^{3}\right)$ & $(45 ; 70 ; 100) \mathrm{m}^{3}$ & $(4 ; 5 ; 6 ; 7)$ & $(6 ; 7 ; 8 ; 9)$ \\
\hline D & $(0.12 ; 0.24 ; 0.34 ; 0.40)\left(\mathrm{m}-\mathrm{h} / \mathrm{m}^{3}\right)$ & $(600 ; 700 ; 900) \mathrm{m}^{3}$ & $(4 ; 5 ; 6 ; 7)$ & $(2 ; 3 ; 4 ; 5)$ \\
\hline
\end{tabular}

Table 4. Summary of calculation results on the basis of Table 3

\begin{tabular}{|c|c|c|c|c|c|}
\hline \multirow{2}{*}{ Work } & \multicolumn{2}{|c|}{ The earliest fuzzy deadlines } & \multirow{2}{*}{ Reserve time } & \multicolumn{2}{|c|}{ The latest fuzzy deadlines } \\
\cline { 2 - 3 } \cline { 5 - 6 } & of beginning & of completion & & of beginning & of completion \\
\hline S & $(0,0,0,0)$ & $(0,0,0,0)$ & $(0,0,0,0)$ & $(0,0,0,0)$ & $(0,0,0,0)$ \\
\hline A & $(0,0,0,0)$ & $(5,6,6,7)$ & $(1,3,4,4)$ & $(1,3,4,4)$ & $(6,9,10,11)$ \\
\hline B & $(0,0,0,0)$ & $(10,13,14,15)$ & $(0,0,0,0)$ & $(0,0,0,0)$ & $(10,13,14,15)$ \\
\hline C & $(5,6,6,7)$ & $(11,13,14,16)$ & $(1,3,4,4)$ & $(6,9,10,11)$ & $(12,16,18,20)$ \\
\hline D & $(10,13,14,15)$ & $(12,16,18,20)$ & $(0,0,0,0)$ & $(10,13,14,15)$ & $(12,16,18,20)$ \\
\hline F & $(12,16,18,20)$ & $(12,16,18,20)$ & $(0,0,0,0)$ & $(12,16,18,20)$ & $(12,16,18,20)$ \\
\hline
\end{tabular}




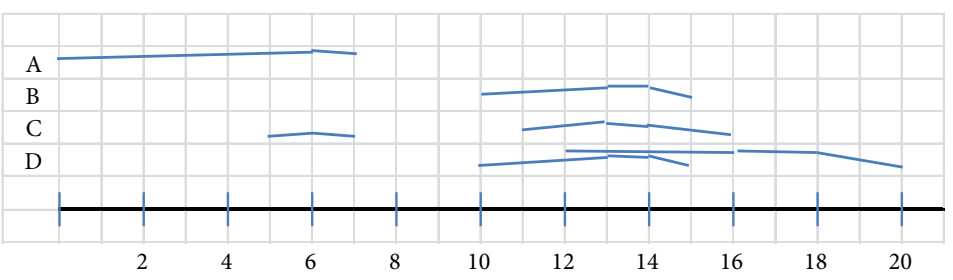

Figure 3. Schedule according to the earliest dates using fuzzy values

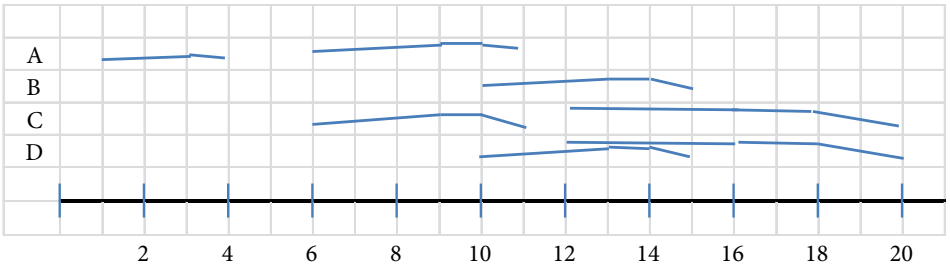

Figure 4 . Schedule according to the latest dates using fuzzy values

uncertainty regarding the completion of important tasks or the entire project. It can then be used to analyze the risk of exceeding the critical deadline. When comparing the schedule based on deterministic and fuzzy data, one can notice greater flexibility in shaping the fuzzy schedule and the possibility of taking into account a wider range of risk in it than with the deterministic schedule.

\section{Cost estimation - Fuzzy Case Based Reasoning Cost Support Method}

The example shown is quite specific, as it concerns a situation involving fuzzy information during cost estimation works. The example uses fuzzy inference from CBR cases, which allowed to increase the accuracy and correctness of cost calculations performed for the investor in the construction and investment process with some degree of fuzziness of the available information about materials or technologies used. Supporting cost calculations can be based on available historical data, therefore, the research was based on the investigation of numerous studies. In the case of unclear or imprecise data, the fuzzy sets theory was applied to determine the similarity of cases. Below the authors present the original FCBR CSM (Fuzzy Case Based Reasoning Cost Support Method). Figure 5 illustrates the workflow.

The first step in the FCBR CSM method is the description of a new problem consisting in the valuation of works or construction works. First, inaccurate information should be written in the form of a fuzzy number and the shape of the membership function should be determined. The concept of fuzzy sets allows not only "precise" assessment using the value of 0 or 1 , but using the membership function also to use intermediate values in the set $\{0,1\}$ (Zima, 2015). The next step in the model is to find the most similar case in the available database of "old" cases. The assessment of similarity is made by determining the fuzzy distance between the cases. The case or cases for which the similarity is greater than $95 \%$ are entered into

$$
\text { Fuzzy data Fuzzy distance measure }
$$

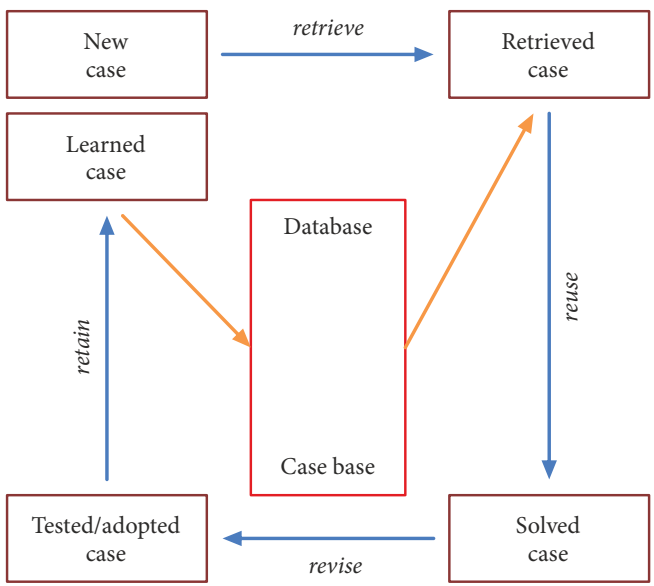

Figure 5. Proposed FCBR CSM workflow (own study)

the initial set of solutions - the Solved Case. The solution sought is the unit prices of construction works and, based on old cases, unit prices are the solution sought. Then the solutions found (the old cases) are tested and adapted. If a given case deviates from the selected solutions, it is removed from the initial set of solutions. When the time of occurrence or the location of the old case are different from the new case, the solution is adapted by adjusting the unit price by the inflation rate and the regional factor. The last step is to reuse the new case by entering it into the database after determining the unit price that is to be determined - the Case Base.

An important step in the given procedure is finding cases similar to the new one, and thus to calculate the similarities of cases, namely, distances between cases. It should be emphasized that the reliability of the calculations is influenced not only by the fuzzy data, but also by the method of evaluation itself, that is the selected shape of the membership function and the calculation formula that allows for the assessment of the similarity of cases. 
For example, a trapezoidal shape is often chosen as the basic shape, which may be rectangular or triangular in special cases. There are also several ways to calculate the distance between cases using the formulas for the distance between two fuzzy sets (Table 5).

The original definition of set equality given by Zadeh (1965) states that sets $A$ and $B$ are equal:

$$
\forall_{u \in U} \mu_{A}(u)=\mu_{B}(u) \text {. }
$$

Generally, however, the measure of similarity must be less restrictive so that the similarity can take any values in the range $[0,1]$ according to the possibilities offered by the fuzzy number theory. Yet the calculation formula depends on the adopted shape of the membership function. Given two trapezoidal fuzzy numbers $A_{N C}=\left(a_{1}, a_{2}, a_{3}, a_{4}\right)$ and $B_{C i}=\left(b_{1}, b_{2}, b_{3}, b_{4}\right)$, similarity $\operatorname{sim}\left(A_{N C}, B_{C i}\right)$ can be specified, for example, by the following formula:

$$
\operatorname{sim}\left(A_{N C}, B_{C i}\right)=1-\frac{\sum_{i=1}^{4}\left|a_{i}-b_{i}\right|}{4},
$$

where: $\operatorname{sim}\left(A_{N C}, B_{C i}\right)$ - similarity between fuzzy numbers, $A_{N C}$ - fuzzy number for the new case, $B_{C i}$ - fuzzy number for the old case taken from the database, and $a_{i}$, - characteristic points for fuzzy numbers $A_{N C}=\left(a_{1}, a_{2}, a_{3}, a_{4}\right)$ and $B_{C i}=\left(b_{1}, b_{2}, b_{3}, b_{4}\right)$.

The characteristic points allow for describing the limit values for the shape of the membership function that accepts the values 0 and 1 . This allows for describing the fuzzy number using the four real numbers, which allows for the quick execution of actions using only these characteristic point values. When adopting other forms of membership functions, other calculation formulas should be used (Leśniak \& Zima, 2018).

After analyzing the local similarities, namely the similarities generated for individual variables, the global similarity is calculated using the weights of individual variables:

$$
\operatorname{SIM}\left(V_{N}, V_{S j}\right)=\sum_{i=1}^{n} \omega_{i}\left(\operatorname{sim}_{i}\left(V_{N i}, V_{S j i}\right)\right),
$$

where $\omega_{i}$ - weight of the $i$-th explanatory variable; $\operatorname{SIM}\left(V_{N}, V_{j}\right)$ - global similarity between the old case $V_{j}$, and a new case $V_{N} ; \operatorname{sim}_{i}\left(V_{N i}, V_{S j i}\right)$ - local similarity for $i$-th explanatory variable between old case $V_{j}$, and a new case $V_{N}$.

In the example, however, only cases with unclear or imprecise data were analyzed, assuming that when calculating unit prices for precise data, prices can be determined without using fuzzy sets or using the singleton shape function.

An example using the above methodology is shown below. When ordering works consisting in the construction of a football pitch with an artificial surface for construction work, defined in accordance with the OmniClass classification as "21-06 106030 Sports field surfaces", the investor specified the thickness of the ELTAN P polyurethane surface layer (Figure 6) of the field with an area of $1080 \mathrm{~m}^{2}$ as $\mathrm{min} .30 \mathrm{~mm}$. However, the thickness of more than $40 \mathrm{~mm}$ is fully satisfactory for the investor.

For the New Case, the shape of the membership function with the characteristic points is shown in Figure 7. Investor requirements can be recorded using a fuzzy number, in this case as a fuzzy set $A_{\text {New Case }}=(0.3 ; 0.4 ; 0.6$; 0.6 ), which means adopting the minimum value for the thickness of the polyurethane surface as $30 \mathrm{~mm}$, and the values already fully satisfactory to the investor in the range of $40-60 \mathrm{~mm}$.

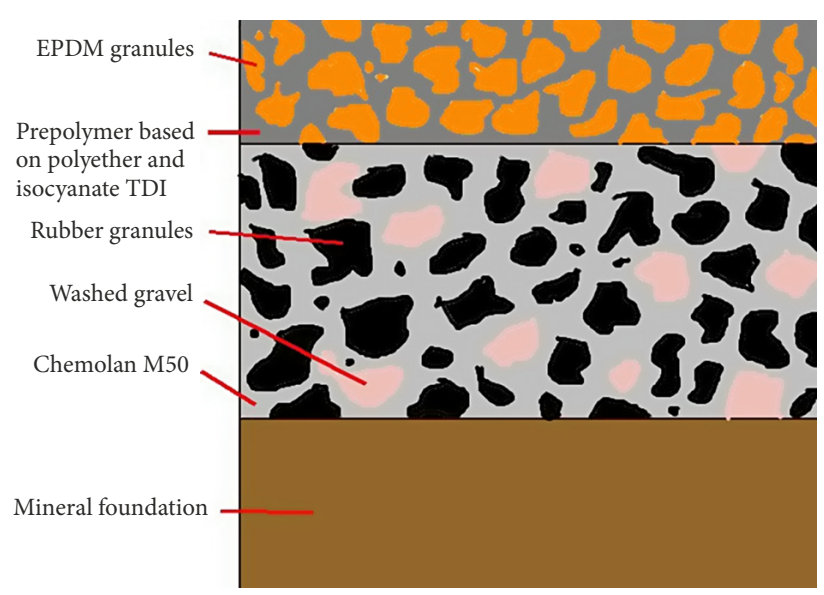

Figure 6. Diagram of the cross-section of the Eltan P surface

Table 5. Examples of the calculation of the fuzzy distance between the fuzzy sets A and B

\begin{tabular}{|l|l|l|}
\hline \multicolumn{1}{|c|}{ Formula name } & \multicolumn{1}{|c|}{ Calculation formula } & \multicolumn{1}{c|}{ Comments } \\
\hline Fuzzy Euclidean Distance & $d(A, B)=\sqrt{\sum_{i=1}^{n}\left(A\left(\mathrm{x}_{\mathrm{i}}\right)-B\left(x_{i}\right)\right)^{2}}$ & $\begin{array}{l}A\left(x_{i}\right), B\left(x_{i}\right)-\text { fuzzy sets, } \\
d(A, B)-\text { distance between the sets } A \text { and } B, \\
i-\text { space dimension from } 1 \text { to } n .\end{array}$ \\
\hline Generalized Hamming distance & $d(A, B)=\sum_{i=1}^{n}\left|A\left(x_{i}\right)-B\left(x_{i}\right)\right|$ & $\begin{array}{l}A\left(x_{i}\right), B\left(x_{i}\right) \text { - fuzzy sets, } \\
d(A, B)-\text { distance between the sets } A \text { and } B, \\
i-\text { space dimension from } 1 \text { to } n .\end{array}$ \\
\hline Extended Jaccard Index & $d(A, B)=\frac{|A B|}{|A B|}$ & $\begin{array}{l}\text { } \text { and } \cup \text { can be any t-norm and s-norm, respectively } \\
\text { Ramli \& Mohamad, 2010). }\end{array}$ \\
\hline Hausdorff metric & $d(A, B)=\max (\sigma(A, B), \sigma(B, A))$ & $\begin{array}{l}\sigma(A, B)-\text { interval of set } A \text { from set } B, \\
\sigma(B, A)-\text { interval of set } B \text { from set } A .\end{array}$ \\
\hline
\end{tabular}


a)

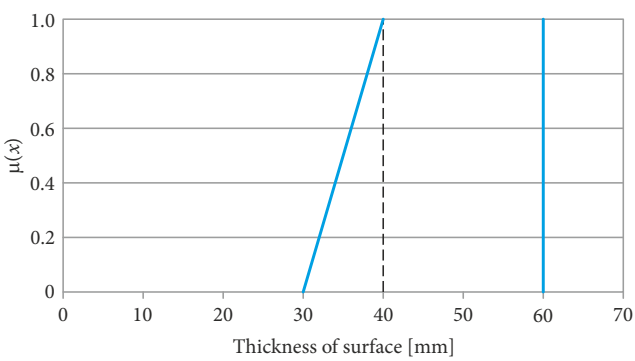

b)

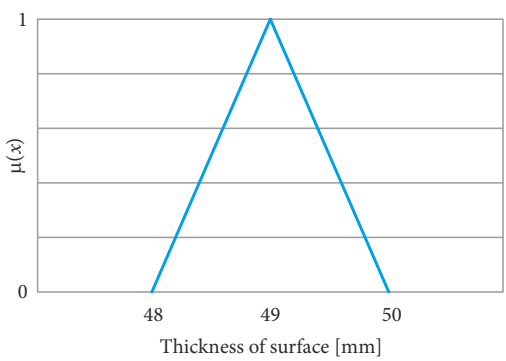

c)

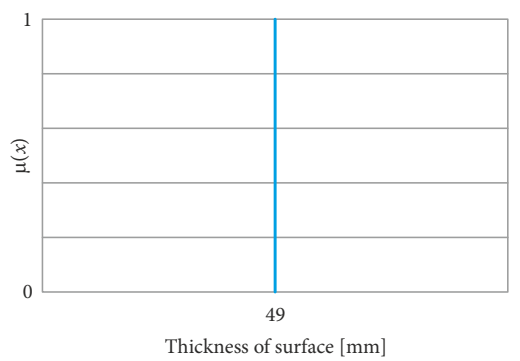

Figure 7. Membership function for the variable explaining the surfaces of football surfaces - New Case (source: own study)

In accordance with the scheme of operation of the CBR method (Figure 5), the New Case was compared with old cases included in the database. For example, for the Old Case 1 from the database - the Case Base, the thickness of the polyurethane surface layer for which the unit price is known was $49 \mathrm{~mm}$, and the pitch area was $1196 \mathrm{~m}^{2}$. This can be written as a fuzzy number $B_{\text {Old Case } 1}=(0.48 ; 0.49$; $0.49 ; 0.50)$, which in practice means rejection of solutions other than $49 \mathrm{~mm}$ (Figure 7a). One can also write such a fuzzy number as a singleton (Figure $7 \mathrm{~b}$ ).

In the case of assuming two fuzzy numbers with trapezoidal shapes $A_{\text {New Case }}=(0.3 ; 0.4 ; 0.6 ; 0.6)$, and $B_{\text {Old Case } 1}=(0.48 ; 0.49 ; 0.49 ; 0.50)$, the calculation of the similarity of cases is as follows:

$\operatorname{sim}_{\text {thicknes of surface }}\left(A_{\text {New Case }}, B_{\text {Old Case } 1}\right)=$

$1-\frac{|0.3-0.48|+|0.4-0.49|+|0.6-0.49|+|0.6-0.50|}{4}=0.88$

The remaining variables for the construction work consisting in the execution of the surface of football fields were calculated on the basis of classical mathematics.

For comparison, the size of the playing fields (area of New Case $=1080 \mathrm{~m}^{2}$, area of Old Case $1=1196 \mathrm{~m}^{2}$ ):

$\operatorname{sim}_{\text {pitch surface }}\left(A_{\text {New Case }}, B_{\text {Old Case } 1}\right)=1-\frac{|1080-1196|}{7500-0}=0.98$.

For comparison, the type of surface (the same)

$\operatorname{sim}_{\text {surface type }}\left(A_{\text {New Case }}, B_{\text {Old Case } 1}\right)=1-\frac{|1-1|}{2-1}=1$.

For the construction work in question the following weights $\omega_{i}$ were defined for the subsequent explanatory variables (Table 6). For this purpose, the correlation coefficients of individual explanatory variables with the price of the selected work or construction element were used. Correlations were calculated for measurable variables using the Pearson linear correlation coefficient, and for variables having a qualitative Spearman sequential correlation coefficient. An assumption was also made to reject explanatory variables with little or no correlation according to the J. Guilford scale.

The weight of the explanatory variables was determined from the following formula:
Table 6. Correlations and the weight of explanatory variables for the construction work "21-06 106030 Sports field surfaces" (source: own study)

\begin{tabular}{|l|c|c|c|}
\hline $\begin{array}{c}\text { Explanatory } \\
\text { variables }\end{array}$ & $\begin{array}{c}\text { Surface } \\
\text { type }\end{array}$ & $\begin{array}{c}\text { Layer thickness } \\
{[\mathrm{mm}]}\end{array}$ & $\begin{array}{c}\text { Amount of } \\
\text { works }\left[\mathrm{m}^{2}\right]\end{array}$ \\
\hline $\begin{array}{l}\text { Type of } \\
\text { correlation }\end{array}$ & Spearman & Pearson & Pearson \\
\hline Correlation & -0.697560 & -0.683694 & -0.566591 \\
\hline $\begin{array}{l}\text { Correlation } \\
\text { absolute value }\end{array}$ & 0.697560473 & 0.683694442 & 0.566590849 \\
\hline Weights & $35.81 \%$ & $35.10 \%$ & $29.09 \%$ \\
\hline
\end{tabular}

$$
\omega_{i}(21-07107020)=\frac{\left|r_{i}\right|}{\sum_{i=1}^{n}\left|r_{i}\right|}
$$

where: $\omega_{i}$ - weight of the $i$-th explanatory variable for the construction work "Sports field surfaces", $r_{i}-$ correlation coefficient for the $i$-th explanatory variable, $n$ - number of explanatory variables for the construction work "Sports field surfaces".

For example, for the explanatory variable "Layer thickness" the weight is:

$$
\omega_{1}=\frac{\left|r_{1}\right|}{\sum_{i=1}^{n}\left|r_{i}\right|}=\frac{0.683694442}{1.947845764}=0.351000297=35.10 \% \text {. }
$$

Partial global similarity SIM $^{\text {surface }}$ for Old Case 1 is therefore equal to $\mathrm{SIM}^{\text {surface }}$ (Case 1 ) $=0.3581 \cdot 1+$ $0.3510 \cdot 0.88+0.2909 \cdot 0.98=0.95$, where the values 0.3581 , $0.3510,0.2909$ are the determined weights of individual features describing the construction work.

Two cases - the presented Case 1 and Case 10 from a database of 69 cases, turned out to have the highest similarity of $95 \%$. The unit price of the surface for Old Case 1 was $23.96 € / \mathrm{m}^{2}$, and for Old Case 2 it was $24.84 € / \mathrm{m}^{2}$.

The next step is to adapt the solutions due to the differences in location and time between the New Case and Old Cases 1 and 10. In order to adapt the prices of two selected cases due to their location, regional coefficients were used, calculated by the authors on the basis of the Sekocenbud regional price bulletin (Sekocenbud, 2020a). In order to update the prices of construction investments 
calculated in the past for the time of calculating a new case, the Sekocenbud bulletin of valorization and forecasting indicators was used (Sekocenbud, 2020b).

The calculations related to the adaptation of unit prices of selected Old Cases are presented below:

Old Case 1: $23.96 € / \mathrm{m}^{2} \cdot 1.015 \cdot(1+2.2 \%)=24.85 € / \mathrm{m}^{2}$;

Old Case $10: 24.84 € / \mathrm{m}^{2} \cdot 0.98 \cdot(1+1.2 \%)=24.63 € / \mathrm{m}^{2}$.

The selected unit price as the average of the unit prices is $24.74 € / \mathrm{m}^{2}$. The estimated value of the works for the New Case is the product of the calculated unit price and the pitch area: $1080 \mathrm{~m}^{2} \cdot 24.74 € / \mathrm{m}^{2}=26719.20 €$.

The CBR method is useful even for not very large databases, which is its great advantage over most other methods, including artificial neural networks. Most methods based on past data and requiring a learning process (e.g. neural networks) need much more cases than CBR. The model performs well compared to other models in terms of the mean estimated absolute error, especially the maximum percentage error, where it generates errors similar to neural networks.

\section{Risk quantification - fuzzy measure of the effect of the occurrence of an unwanted phenomenon}

An example of the use of fuzzy sets to assess the effects of technological and construction (implementation) risk factors is the result of many years of research work by the authors, which they conducted on the issue of modelling the life cycle costs of buildings, taking into account risk factors identified in individual phases of their life cycle.

This example presents a proposal for an assessment of the effect (consequences) of an adverse event during the implementation of a construction project based on the interpretation of the results of expert studies for selected risk factors that may be burdened with a high level of dispersion. This is most often caused by the subjective perception of the subject studied by experts and difficulties in unambiguous understanding of the studied feature, which in the case of original research concerned the assessment of the impact of risk on the costs incurred in subsequent phases of the life cycle of buildings.

The authors, in their research work to date, have used the fuzzy set theory in the field of studies on the assessment of risk factors in risk management in construction projects in the perspective of the life cycle of buildings. In subsequent stages, the research covered: identification of risk factors broken down into subsequent phases of the building life cycle (Plebankiewicz et al., 2015), construction of a fuzzy risk assessment model in the life cycle of buildings (Plebankiewicz \& Wieczorek, 2016), choosing the right defuzzification method for the fuzzy risk assessment model under development (Wieczorek, 2018) and checking the correctness of the operation of the fuzzy risk assessment model by performing a series of sensitivity analyses for the possibility of changing parameters that may affect the final result (Plebankiewicz \& Wieczorek, 2018).
As regards the construction of the fuzzy risk factor assessment model, the authors proposed to use the mathematical foundations of the Mamdani fuzzy inference model. The authors' model is of a fuzzy inference type: multi-input-single-output (MISO). In the authors' model, the probability of a given risk factor $\mathrm{PR}(\mathrm{Uph})$ is an input variable $x_{1}$. Input variable $x_{2}$ is the effect (consequence) of its occurrence - EFF(Uph). The following question: "are there any indications that an expert assessing the risk in the life cycle of a building should take into account the impact of the identified risk factor on the size of the corresponding component of the life cycle costs of the building" was defined as the output variable CIR(Uph), namely, $y$. The risk assessor is required to provide as input sharp values of the input variables $x_{1}$ and $x_{2}$, which characterize the identified risk factor to be assessed. As a result of successive processes: fuzzification, inference and sharpening (blocks: B1, B2 and B3), an initial sharp value $y$ is calculated, which is to indicate the answer to the question of the expert assessing the risk about the need to take into account the impact of the identified risk factor on the size of the corresponding component of the life cycle cost.

Figures 8 to 10 show graphic interpretations of linguistic terms $\mathrm{L}(\mathrm{X} 1), \mathrm{L}(\mathrm{X} 2)$ and $\mathrm{L}(\mathrm{Y})$ respectively for the input variables $x_{1}, x_{2}$ and the output variable $y$. The figures include the so-called basic set of membership functions formed by functions with piecewise line graphs, that is triangular functions and $\Gamma$ and $\mathrm{L}$ classes. In publication by Plebankiewicz and Wieczorek (2018) the authors described the possibility of using other, three alternative sets of membership functions, formed by complex functions, that is piecewise quadratic, harmonic and symmetrical, as well as asymmetrical Gaussian functions.

According to the assumptions of the construction of the fuzzy risk assessment model in the life cycle of buildings, the decision-maker assessing them is obliged to provide at the input sharp values of the input variables $x_{1}$ (probability of occurrence of a given risk factor) and $x_{2}$ (the result of the occurrence of a given risk factor), which will describe the identified risk factor being assessed. The domain (universe) of space $\mathrm{X}_{1} \subset[0 ; 1]$ was established as for probability in the mathematical sense, namely individually but in decimal notation. The universe of space $\mathrm{X}_{2} \subset[1,5]$ in turn corresponds to the scale of the impact of individual risk factors on the costs incurred in the life cycle phases of buildings, which was adopted as in the original questionnaire research.

As for the input values for the $x_{2}$ variable, the authors conducted expert questionnaire studies in 2017-2020 to determine the impact of individual risk factors on the costs incurred in the life cycle phases of buildings. For the purposes of the research, the following evaluation scale was adopted: 1 - insignificant, 2 - insignificant, 3 - medium significant, 4 - significant, 5 - very significant, 0 - I cannot assess it. 26 risk factors identified by the authors were assessed (Plebankiewicz et al., 2015) using the opinions of experts with theoretical knowledge and practical experience in the implementation of construction projects of various types, characteristics and degrees of complexity. 
32 experts took part in the study, who gave a total of 832 impact assessments for the identified risk factors of a technological and construction (implementation) character. The calculated values of the risk impact on the size of the life cycle costs of buildings are presented in Table 7 in the perspective of average assessments from the studies. The risk factors of these two categories may occur at any stage of the life cycle of buildings, therefore the relevant information on the assignment of a given risk factor to the corresponding life cycle phases is included in Table 7 (columns d-g).

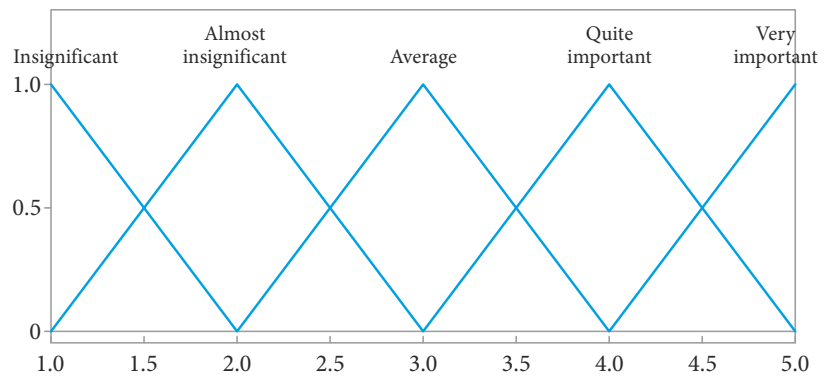

Figure 9. Linguistic terms of the input variable $x_{2}$ (own study)
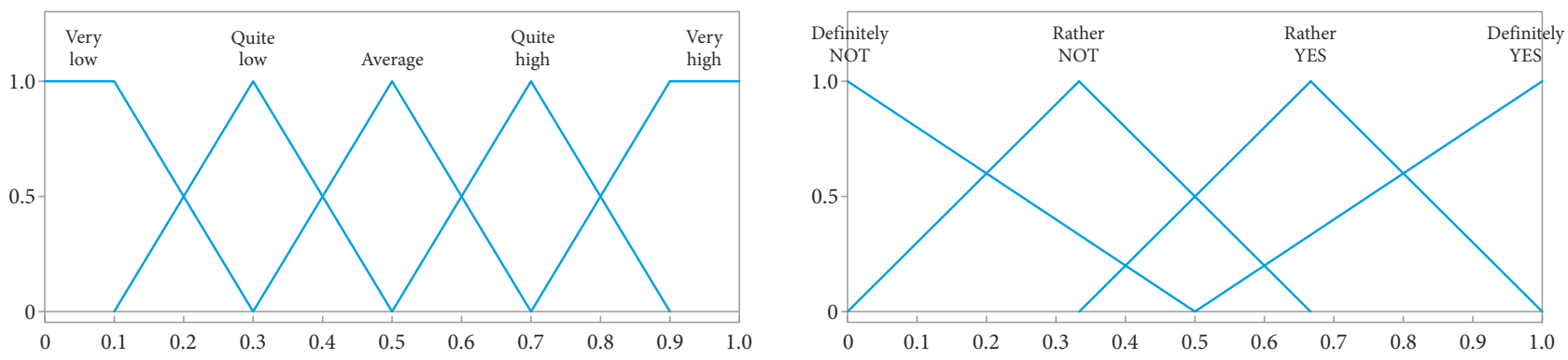

Figure 8. Linguistic terms of the input variable $x_{1}$ (own study)

Figure 10. Linguistic terms of the output variable $y$ (own study)

Table 7. The results of expert studies of the risk impact assessment on the size of the life cycle costs of buildings, taking into account the possibility of the occurrence of a given risk factor at various stages of their life cycle (own study)

\begin{tabular}{|c|c|c|c|c|c|c|c|}
\hline \multirow{2}{*}{$\begin{array}{c}\text { Risk } \\
\text { category }\end{array}$} & \multirow{2}{*}{\multicolumn{2}{|c|}{ Risk factors (RF) }} & \multicolumn{4}{|c|}{ Life cycle phase } & \multirow{2}{*}{ Mean } \\
\hline & & & $\mathrm{P}$ & $\mathrm{C}$ & $\mathrm{O}$ & $\mathrm{W}$ & \\
\hline a & $\mathrm{b}$ & c & $\mathrm{d}$ & $\mathrm{e}$ & $\mathrm{f}$ & $\mathrm{g}$ & $\mathrm{h}$ \\
\hline \multirow{9}{*}{ 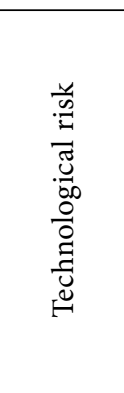 } & 1 & Mistakes in designs & $x$ & & & & 4.19 \\
\hline & 2 & Deficiencies in projects & $x$ & & & & 3.44 \\
\hline & 3 & Non-compliance of projects with applicable standards and / or regulations & $x$ & & & & 3.83 \\
\hline & 4 & Incorrectly identified ground conditions & $x$ & & & & 4.44 \\
\hline & 5 & Incorrectly adopted assumptions for design and material solutions & $x$ & & & & 4.53 \\
\hline & 6 & Shortage of suitably qualified workforce & $x$ & $\times$ & $x$ & & 3.16 \\
\hline & 7 & Variable work performance of construction workers & & $\times$ & $x$ & & 2.41 \\
\hline & 8 & Poor quality of construction equipment & & $\times$ & $x$ & & 2.75 \\
\hline & 9 & Failure frequency of construction equipment & & $x$ & $x$ & & 2.63 \\
\hline \multirow{17}{*}{ 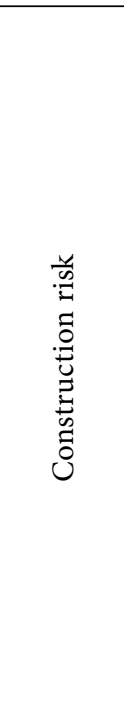 } & 10 & Unfavorable weather conditions & & $\times$ & $\times$ & $\times$ & 2.75 \\
\hline & 11 & Non-compliance with the principles of occupational health and safety during the work & & $\times$ & $x$ & $\times$ & 2.47 \\
\hline & 12 & Suspension of works due to designer's errors & & $\times$ & $x$ & $\times$ & 2.93 \\
\hline & 13 & Changes to the originally approved scope of work & & $\times$ & $\times$ & $\times$ & 3.09 \\
\hline & 14 & Poor quality of the work performed & & $x$ & $x$ & & 4.00 \\
\hline & 15 & Poor quality of management & & $\times$ & $x$ & & 3.41 \\
\hline & 16 & Delays in the implementation of construction works & & $\times$ & $x$ & $\times$ & 3.34 \\
\hline & 17 & Failure to settle obligations with subcontractors and suppliers & & $x$ & $x$ & $\times$ & 2.84 \\
\hline & 18 & Limited availability of reliable subcontractors & & $\times$ & $x$ & & 3.47 \\
\hline & 19 & Poor quality of cooperation with subcontractors and suppliers & & $x$ & $x$ & & 3.00 \\
\hline & 20 & Suspension of works due to contractor's mistakes & & $x$ & $\times$ & $\times$ & 3.74 \\
\hline & 21 & Limited availability of building materials & & $x$ & $x$ & & 2.97 \\
\hline & 22 & Ensuring the continuity of supplies of building materials and systems & & $\times$ & $x$ & & 2.81 \\
\hline & 23 & Use of scarce building materials & & $x$ & $x$ & & 3.71 \\
\hline & 24 & Use of unsuitable building materials & & $x$ & $x$ & & 4.26 \\
\hline & 25 & Limited availability of specialized construction machinery & & $\times$ & $x$ & $\times$ & 2.84 \\
\hline & 26 & Risk resulting from accompanying processes (e.g. transport services) & & $x$ & $x$ & $\times$ & 2.58 \\
\hline
\end{tabular}

Note: $\mathrm{P}$ - programming (designing) phase, $\mathrm{C}$ - construction phase, $\mathrm{O}$ - operation phase, $\mathrm{W}$ - withdrawal phase. 
The authors' observations indicate that for some of the risk factors identified by Plebankiewicz et al. (2015), experts more clearly indicated the greater or lesser significance of the impact on the size of the life cycle costs of buildings. This means risk factors no. 1 (errors in projects), 4 (incorrectly identified ground conditions), 5 (incorrectly adopted assumptions for construction and material solutions), 11 (non-compliance with the principles of occupational health and safety during work), 14 (poor quality works performed) and 24 (use of inappropriate building materials). According to experts, some of the risk factors listed in Table 8 are characterized by a high degree of dispersion of the impact assessments on the size of the life cycle costs of buildings. It is especially noticeable for risk factors for which evaluation results indicating membership at the level equal to or close to the maximum for more than two grades of evaluation were obtained. The authors refer to risk factors no. 12 (suspension of works due to designer's errors), 17 (failure to settle obligations with subcontractors and suppliers), 21 (limited availability of building materials) and 23 (use of scarce building materials). Table 8 summarizes the complete information on the responses provided by experts, providing in columns $\mathrm{c}$ to $\mathrm{h}$ data on the number of responses obtained for individual levels of impact assessment by experts.

According to the authors the high degree of dispersion of the assessments of the impact of risk factors no. 12, 17,21 and 23 on the size of the life cycle costs of buildings is related to the uncertainty of the answers provided by the experts participating in the research. The reason for this uncertainty is most likely the fact that the experts had various functions in construction industry (they were designers, architects, economic specialists in construction companies, construction managers, supervisors, cost estimators and production quality specialists) and represented different areas of activity (construction, assembly, mod- ernization, renovation, installation and finishing works) in different types of buildings (residential, commercial buildings, roads and rail roads, municipal, industrial and historic buildings). Experts could therefore different (more clearly) indicate the impact of selected risk factors on the size of the costs of the life cycle of buildings depending on whether, how often and to what extent a given risk factor affects a given component of the life cycle costs of a building that may be related to this.

Based on the assessment of the impact of risk factors on the size of the life cycle costs of buildings presented in Table 8, and obtained in their own research, the authors defined the measures in the form of fuzzy numbers, using the statistical normalization method of the "min-max" type. This normalization is a scaling process and reduces the data by a linear function to the "new min $_{\text {, }}$ new ${ }_{\max }$ " interval, which in fuzzy logic means the limit (minimum and maximum) degrees of membership at the $[0,1]$ level. Calculation formula of normalization "min-max" is as follows:

$$
x^{\prime}=\frac{x-\min }{\max -\min } \cdot\left(\text { new }_{\max }-\text { new }_{\min }\right)+\text { new }_{\min },
$$

where: $x^{\prime}$ - normalized value (scaled), min, max - minimum and maximum values from the number of expert assessments for the impact assessment scale range from 1

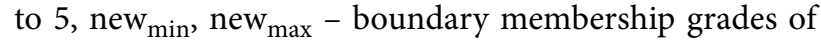
0 and 1 , respectively.

The following Figures 11 and 12 illustrate graphic interpretations of fuzzy numbers for selected risk factors, presented in Table 8.

Table 9 depicts fuzzy measures to assess the impact of risk on the size of the life cycle costs of buildings, which are presented in the perspective of the application of selected defuzzification methods. The data in columns $\mathrm{c}-\mathrm{f}$ correspond to the fuzzy numbers shown in Figures 11 and 12.

Table 8. The results of expert studies of risk impact assessment on the size of the life cycle costs of buildings, taking into account the number of responses received for each degree of impact (own study)

\begin{tabular}{|c|c|c|c|c|c|c|c|}
\hline \multirow{2}{*}{\multicolumn{2}{|c|}{ Risk factors (RF) }} & \multicolumn{6}{|c|}{ Number of expert responses } \\
\hline & & 1 & 2 & 3 & 4 & 5 & \\
\hline $\mathrm{a}$ & $\mathrm{b}$ & c & $\mathrm{d}$ & e & $\mathrm{f}$ & $\mathrm{g}$ & $\mathrm{h}$ \\
\hline \multicolumn{8}{|c|}{ Group of factors clearly assessed - low level of dispersion of experts' opinions } \\
\hline 1 & Mistakes in designs & 0 & 1 & 3 & 17 & 11 & 0 \\
\hline 4 & Incorrectly identified ground conditions & 0 & 0 & 3 & 12 & 17 & 0 \\
\hline 5 & Incorrectly adopted assumptions for design and material solutions & 0 & 0 & 4 & 7 & 21 & 0 \\
\hline 11 & Non-compliance with the principles of occupational health and safety during the work & 6 & 13 & 7 & 4 & 2 & 0 \\
\hline 14 & Poor quality of the work performed & 0 & 4 & 4 & 12 & 12 & 0 \\
\hline 24 & Use of unsuitable building materials & 0 & 3 & 2 & 10 & 16 & 1 \\
\hline \multicolumn{8}{|c|}{ Group of factors assessed ambiguously - high degree of dispersion of experts' assessments } \\
\hline 12 & Suspension of works due to designer's errors & 2 & 9 & 9 & 7 & 2 & 3 \\
\hline 17 & Failure to settle obligations with subcontractors and suppliers & 5 & 8 & 7 & 9 & 2 & 1 \\
\hline 21 & Limited availability of building materials & 2 & 11 & 7 & 10 & 2 & 0 \\
\hline 23 & Use of scarce building materials & 0 & 5 & 8 & 9 & 9 & 1 \\
\hline
\end{tabular}

Note: 1 - insignificant, 2 - insignificant, 3 - medium significant, 4 - significant, 5 - very significant, 0 - I cannot assess it. 

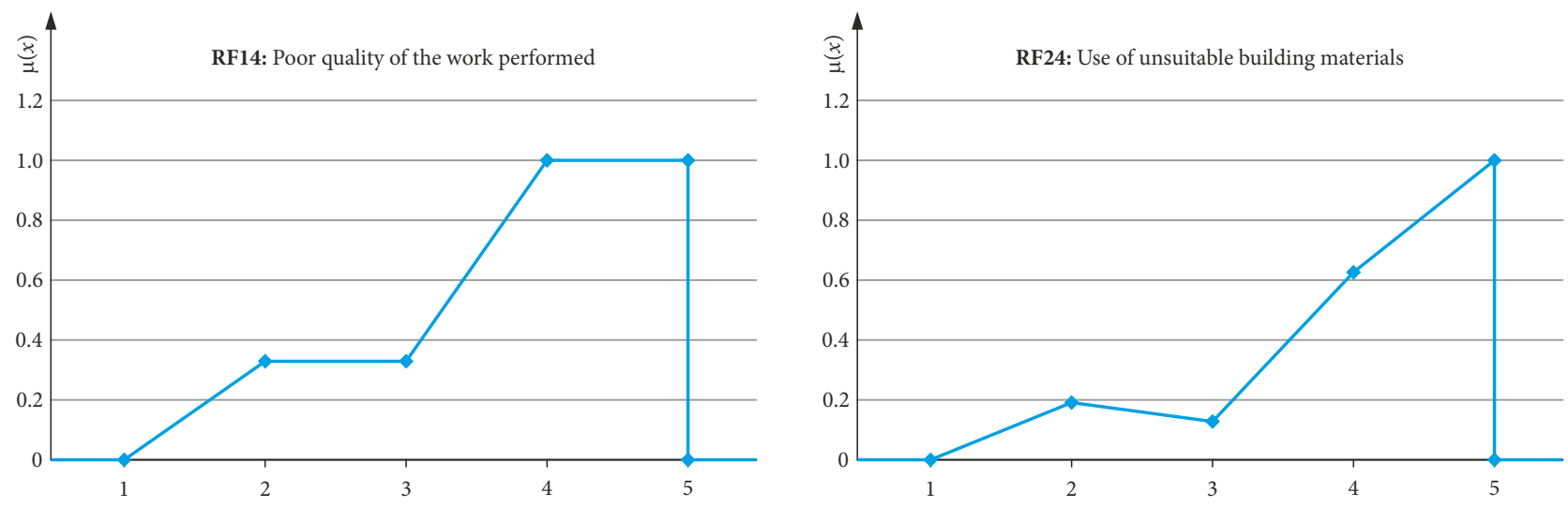

Figure 11. Graphical interpretation of fuzzy numbers for risk factors RF 14 - left and RF 24 - right (own study)
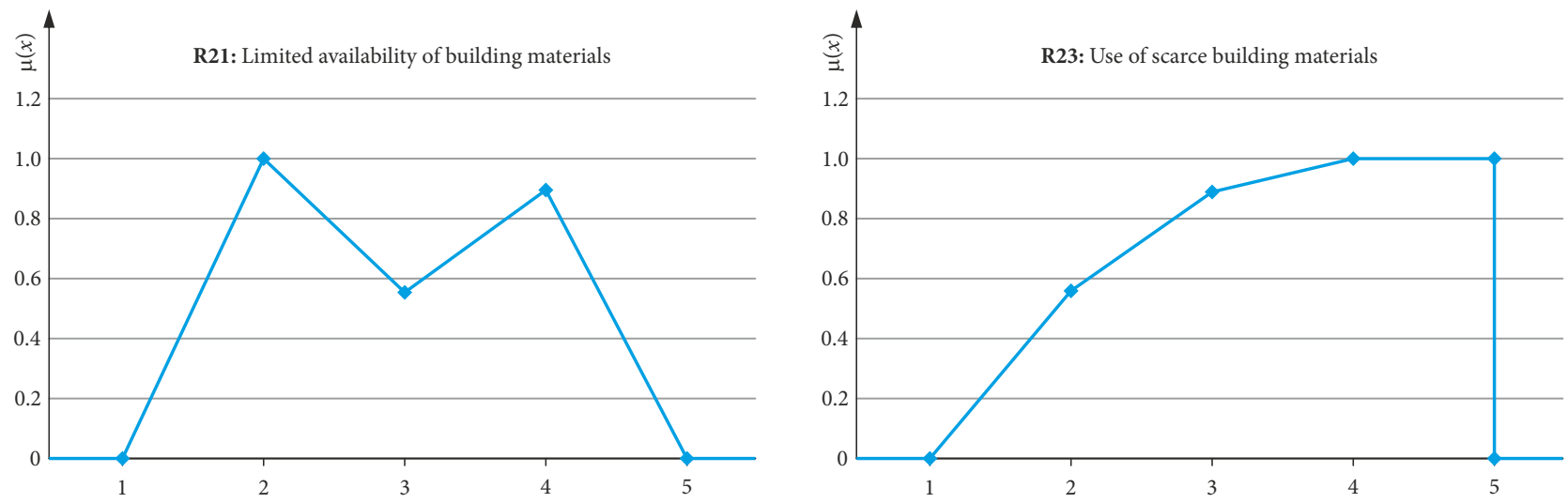

Figure 12. Graphical interpretation of fuzzy numbers for risk factors RF 21 - left and RF 23 - right (own study)

Table 9. The results of expert studies of risk impact assessment on the size of the life cycle costs of buildings in relation to fuzzy measures using various deffuzification methods (own study)

\begin{tabular}{|c|c|c|c|c|c|c|}
\hline \multirow{2}{*}{\multicolumn{2}{|c|}{ Risk factors (RF) }} & \multicolumn{4}{|c|}{ Defuzzification method } & \multirow{2}{*}{ Mean } \\
\hline & & FoM & MoM & LoM & CoG & \\
\hline $\mathrm{a}$ & $\mathrm{b}$ & c & $\mathrm{d}$ & e & $\mathrm{f}$ & g \\
\hline \multicolumn{7}{|c|}{ Group of factors clearly assessed - low level of dispersion of experts' opinions } \\
\hline 1 & Mistakes in designs & 4.00 & 4.00 & 4.00 & 3.95 & 4.19 \\
\hline 4 & Incorrectly identified ground conditions & 5.00 & 5.00 & 5.00 & 4.11 & 4.44 \\
\hline 5 & Incorrectly adopted assumptions for design and material solutions & 5.00 & 5.00 & 5.00 & 4.13 & 4.53 \\
\hline 11 & Non-compliance with the principles of occupational health and safety during the work & 2.00 & 2.00 & 2.00 & 2.38 & 2.47 \\
\hline 14 & Poor quality of the work performed & 4.00 & 4.50 & 5.00 & 3.69 & 4.00 \\
\hline 24 & Use of unsuitable building materials & 5.00 & 5.00 & 5.00 & 3.88 & 4.26 \\
\hline \multicolumn{7}{|c|}{ Group of factors assessed ambiguously - high degree of dispersion of experts' assessments } \\
\hline 12 & Suspension of works due to designer's errors & 2.00 & 2.50 & 3.00 & 2.89 & 2.93 \\
\hline 17 & Failure to settle obligations with subcontractors and suppliers & 4.00 & 4.00 & 4.00 & 2.92 & 2.84 \\
\hline 21 & Limited availability of building materials & 2.00 & 2.00 & 2.00 & 2.95 & 2.97 \\
\hline 23 & Use of scarce building materials & 4.00 & 4.50 & 5.00 & 3.43 & 3.71 \\
\hline
\end{tabular}

Note: FoM - first of maxima, MoM - middle of maxima, LoM - last of maxima, CoG - centre of gravity.

As shown by the sensitivity analysis performed for the data presented in Table 9 (columns c-g), risk factors from the group of factors with a low degree of dispersion of expert assessments (risk factors 1, 4, 5, 11, 14 and 24) are characterized by lower variability of results than risk fac- tors from the group with a highly dispersed expert opinion. The results of the sensitivity analysis are included in Table 10. In the first group, the coefficients of variation $V$ ranged from $2.31 \%$ for factor 1 (mistakes in designs) to $12.16 \%$ for factor 14 (poor quality of the work performed). 
Table 10. Sensitivity analysis results for risk factors for which fuzzy measures of risk impact on the size of the life cycle costs of buildings were defined (own study)

\begin{tabular}{|c|c|c|c|c|}
\hline \multicolumn{2}{|r|}{ Risk factors (RF) } & $m$ & $s$ & $V$ \\
\hline a & $\mathrm{b}$ & $\mathrm{c}$ & $\mathrm{d}$ & e \\
\hline \multicolumn{5}{|c|}{ Group of factors clearly assessed - low level of dispersion of experts' opinions } \\
\hline 1 & Mistakes in designs & 4.03 & 0.09 & $2.31 \%$ \\
\hline 4 & Incorrectly identified ground conditions & 4.71 & 0.41 & $8.79 \%$ \\
\hline 5 & Incorrectly adopted assumptions for design and material solutions & 4.73 & 0.39 & $8.31 \%$ \\
\hline 11 & Non-compliance with the principles of occupational health and safety during the work & 2.17 & 0.23 & $10.83 \%$ \\
\hline 14 & Poor quality of the work performed & 4.24 & 0.52 & $12.16 \%$ \\
\hline 24 & Use of unsuitable building materials & 4.63 & 0.53 & $11.38 \%$ \\
\hline \multicolumn{5}{|c|}{ Group of factors assessed ambiguously - high degree of dispersion of experts' assessments } \\
\hline 12 & Suspension of works due to designer's errors & 2.66 & 0.42 & $15.73 \%$ \\
\hline 17 & Failure to settle obligations with subcontractors and suppliers & 3.55 & 0.61 & $17.29 \%$ \\
\hline 21 & Limited availability of building materials & 2.38 & 0.53 & $22.06 \%$ \\
\hline 23 & Use of scarce building materials & 4.13 & 0.63 & $15.21 \%$ \\
\hline
\end{tabular}

Note: $m$ - arithmetic average, $s$ - standard deviation, $V$ - coefficient of variation.

However, in the second group, the coefficients of variation $V$ ranged from $15.21 \%$ for factor 23 (use of scarce building materials) to $22.06 \%$ for factor 21 (limited availability of building materials).

Summing up, the authors' research shows that each of the risk factors, which was subject to expert assessment of the risk impact on the size of the life cycle costs of buildings, can be described by means of a measure in the form of a normalized convex or concave fuzzy number. Various deffuzification methods can be used for these fuzzy measures, including the first, middle and last maximum methods as well as the centre of gravity method. By choosing the appropriate deffuzification method for the individually considered impact of the risk factor on the size of the life cycle costs of buildings, the decision-maker assessing the risk using the original fuzzy risk assessment model in the life cycle of buildings can enter the value of the input variable $x_{2}$, not only as the mean value obtained from 32 expert answers (in accordance with Table 7, column h), but also as a sharp value resulting from the application of one of the deffuzification methods, namely the first, middle, last maximum or centre of gravity method (in accordance with Table 9, columns c-f), if, in the opinion of the decision maker, a given sharp value will better represent the effect (consequence) of the occurrence of a given risk factor within the assessment of a given construction project than the average value resulting directly from the authors' research.

\section{Discussion}

The paper presents examples of propositions of solving problems related to time, costs and risk in construction, which are original studies.

The first model involved building a schedule based on uncertain and imprecise data in the form of fuzzy norms, the number of works and the number of employ- ees. Comparing the schedule based on deterministic and fuzzy data, one can notice greater flexibility in shaping the fuzzy schedule and the possibility of taking into account a wider range of risk in it than in the deterministic schedule.

The basis of the next example is a case based reasoning using the fuzzy number theory used to support cost calculation and named by the authors FCBR CSM (Fuzzy Case Based Reasoning Cost Support Method). The conducted analyzes allow for the conclusion that the calculation of the similarities of the cases in the examined problem of the calculation of construction costs allows for a more precise selection of similar cases and the determination of a more appropriate unit price of works. The CBR method is useful even for not very large databases, which is its great advantage over most other methods, including artificial neural networks. Most methods based on past data and requiring a learning process (e.g. neural networks) need much more cases than CBR. The advantages of the model are also low sensitivity to changes in the importance of criteria, low requirements for the acquired knowledge, because the CBR method does not require extracting formal rules from the analysed phenomena, which allows for simplification of reasoning. The fuzzy CBR cost estimation model maintains high quality of solutions and has the ability to generate a correct solution despite the lack of precision of some of the information held. Of course, in the presented method, we can talk about a learning process that takes place by collecting new cases in a database and making them available for solving new problems in the future. The disadvantages of the presented method include the possible lack of finding a similar solution due to the lack of such a solution in the case base, the necessity to adapt and verify the cases due to the passage of time and the lack of $100 \%$ matching, and the lack of optimal solutions - the model usually provides good or rational solutions.

In the last of the proposed models, the authors used the mathematical foundations of the Mamdani fuzzy in- 
ference model to build a model of fuzzy assessment of risk factors. The author's model is a multi-input-single-output fuzzy inference model (MISO). The research conducted shows that each of the risk factors, which was subject to expert assessment of the risk impact on the size of the life cycle costs of buildings, can be described by means of a measure in the form of a convex or concave fuzzy number. Various deffuzification methods can be used for these fuzzy measures, including the first, middle and last maximum methods as well as the center of gravity method. By choosing the appropriate deffuzification method for the individually considered impact of the risk factor on the size of the life cycle costs of buildings, the decision-maker assessing the risk using the original fuzzy risk assessment model. The main advantage of the model of fuzzy assessment of risk factors is its universality. The model can be used to assess the impact of different risk categories on the life cycle costs of buildings. Technological and construction risk factors are not the only risk category that can be assessed using the model. The authors of this paper also conducted research on expert risk assessment of financial, political, ecological and legal nature (Plebankiewicz et al., 2015), the impact of which on the size of the life cycle costs of buildings can also be assessed using the model of fuzzy assessment of risk factors. A disadvantage of the proposed approach to the assessment of risk factors in the life cycle of buildings may be the high degree of dispersion of the assessments of the impact of risk factors on the size of the life cycle costs of buildings that can be related to the uncertainty of the answers provided by the experts participating in the research. Therefore, the fuzzy set theory was used to not only describe the assumptions and build the model of fuzzy assessment of risk factors, but also to analyze the data collected in the research.

\section{Conclusions}

The analysis of the time, costs and risks associated with a construction investment, taking into account the uniqueness of each investment and the variability of its implementation conditions, is an extremely difficult and complex task. As indicated by the literature review, researchers very often use fuzzy logic to solve these problems.

The authors showed the approach to risk in terms of time and cost (the most commonly accepted). The aim of the authors was to show the possibility of using fuzzy sets in decision making in construction in the broadest possible scope, not just on one example. In line with this objective, time and cost analyzes are shown with different examples to show the possibilities of use in different construction works. The relationship between these different examples is the use of fuzzy sets in making decisions when planning costs and time for various buildings.

\section{Author contributions}

$\mathrm{EP}$ and $\mathrm{KZ}$ conceived the study and were responsible for the design and development of the data analysis. EP, KZ and DW were responsible for data collection and analysis. EP wrote the first draft of the article. All authors have read and agreed to the published version of the manuscript.

\section{Disclosure statement}

We declare that we not have any competing financial, professional, or personal interests from other parties.

\section{References}

Abdelgawad, M., \& Fayek, A. R. (2011). Comprehensive hybrid framework for risk analysis in the construction industry using combined failure mode and effect analysis, fault trees, event trees, and fuzzy logic. Journal of Construction Engineering and Management, 138(5), 642-651.

https://doi.org/10.1061/(ASCE)CO.1943-7862.0000471

Amadi, A. I., \& Higham, A. (2017). Latent geotechnical pathogens inducing cost overruns in highway projects. Journal of Financial Management of Property and Construction, 22(3), 269-285. https://doi.org/10.1108/JFMPC-03-2017-0008

Antucheviciene, J., Kala, Z., Marzouk, M., \& Vaidogas, E. R. (2015). Solving civil engineering problems by means of fuzzy and stochastic MCDM methods: Current state and future research. Mathematical Problems in Engineering, Article ID 362579. https://doi.org/10.1155/2015/362579

Bhaskar, T., Manabendra, N. P., \& Asim, K. P. (2011). A heuristic method for RCPSP with fuzzy activity times. European Journal of Operational Research, 208, 57-66. https://doi.org/10.1016/j.ejor.2010.07.021

Castro-Lacouture, D., Süer, G. A., Gonzalez-Joaqui, J., \& Yates, J. K. (2009). Construction project scheduling with time, cost, and material restrictions using fuzzy mathematical models and critical path method. Journal of Construction Engineering and Management, 135(10), 1096-1104.

https://doi.org/10.1061/(ASCE)0733-9364(2009)135:10(1096)

Chanas, S., \& Zielinski, P. (2001). Critical path analysis in the network with fuzzy activity times. Fuzzy Sets \& Systems, 122, 195-204. https://doi.org/10.1016/S0165-0114(00)00076-2

Chen, S., \& Hsueh, Y. (2008). A simple approach to fuzzy critical path analysis in project networks. Applied Mathematical Modelling, 32, 1289-1297.

https://doi.org/10.1016/j.apm.2007.04.009

Cheng, M. Y., Tsai, H. C., \& Sudjono, E. (2010). Conceptual cost estimates using evolutionary fuzzy hybrid neural network. Expert Systems with Applications, 37, 4224-4231.

https://doi.org/10.1016/j.eswa.2009.11.080

Dikmen, I., Birgonul, M. T., \& Han, S. (2007). Using fuzzy risk assessment to rate cost overrun risk in international construction projects. International Journal Project Management, 25, 494-505. https://doi.org/10.1016/j.ijproman.2006.12.002

Ebrahimnejad, S., Mousavi, S., Tavakkoli-Moghaddam, M. R., \& Heydar, M. (2014). Risk ranking in mega projects by fuzzy compromise approach: A comparative analysis. Journal of Intelligent and Fuzzy Systems, 26(2), 949-959. https://doi.org/10.3233/IFS-130785

El-Maaty, A. E. A., El-Kholy, A. M., \& Akal, A. Y. (2017). Modeling schedule overrun and cost escalation percentages of highway projects using fuzzy approach. Engineering, Construction and Architectural Management, 24(5), 809-827. https://doi.org/10.1108/ECAM-03-2016-0084 
Elizabeth, S., \& Sujatha, L. (2013). Fuzzy critical path problem for project network. International Journal of Pure and Applied Mathematics, 85, 223-240.

https://doi.org/10.12732/ijpam.v85i2.4

Ghorabaee, M. K., Amiri, M., Zavadskas, E. K., \& Antucheviciene, J. (2018). A new hybrid fuzzy MCDM approach for evaluation of construction equipment with sustainability considerations. Archives of Civil and Mechanical Engineering, 18(1), 32-49. https://doi.org/10.1016/j.acme.2017.04.011

Han, T., Chung, C., \& Liang, G. (2006). Application of fuzzy critical path method to airports cargo ground operation systems. Journal of Marine Science and Technology, 14, 139-146.

Hashemi, S. S., Razavi, H., Hajiagha, S. H. R., Zavadskas, E. K., \& Mahdiraji, H. A. (2016). Multicriteria group decision making with ELECTRE III method based on interval-valued intuitionistic fuzzy information. Applied Mathematical Modelling, 40(2), 1554-1564. https://doi.org/10.1016/j.apm.2015.08.011

Ibadov, N. (2019). Construction project planning under fuzzy time constraint. International Journal of Environmental Science and Technology, 16, 4999-5006.

https://doi.org/10.1007/s13762-018-1695-x

Islam, M. S., Nepal, M., Skitmore, M., \& Attarzadeh, M. (2017). Current research trends and application areas of fuzzy and hybrid methods to the risk assessment of construction projects. Advanced Engineering Informatics, 33, 112-131. https://doi.org/10.1016/j.aei.2017.06.001

Islam, M. S., Nepal, M., \& Skitmore, M. (2019). Modified fuzzy group decision-making approach to cost overrun risk assessment of power plant projects. Journal of Construction Engineering and Management, 145(2), 04018126. https://doi.org/10.1061/(ASCE)CO.1943-7862.0001593

Khalilzadeh, M., Shakeri, H., Gholami, H., \& Amini, L. (2017). A heuristic algorithm for project scheduling with fuzzy parameters. Procedia Computer Science, 121, 63-71.

https://doi.org/10.1016/j.procs.2017.11.010

Kim, S. Y., Pham, H., \& Luu, T.V. (2018). Construction cost overruns in transmission grid projects. International Journal of Engineering Research and Technology, 11(12), 1923-1948.

Knight, K., \& Fayek, A. R. (2002). Use of fuzzy logic for predicting design cost overruns on building projects. Journal of Construction Engineering and Management, 128(6), 503-512. https://doi.org/10.1061/(ASCE)0733-9364(2002)128:6(503)

Kumar, A., \& Kaur, P. (2010). A new method for fuzzy critical path analysis in project networks with a new presentation of triangular fuzzy numbers. Applications and Applied Mathematics, 5, 1442-1466.

Latief, Y., Wibowo, A. \& Isvara, W. (2013). Preliminary cost estimation using regression analysis incorporated with adaptive neuro fuzzy inference system. International Journal of Technology, 1, 63-72.

Leśniak, A., \& Zima, K. (2018). Cost calculation of construction projects including sustainability factors using the Case Based Reasoning (CBR) method. Sustainability, 10, 1608. https://doi.org/10.3390/su10051608

Meharie, M. G., Abiero, G. Z. C., Mutuku, R. N. N., \& Mengesha, W. J. (2019). An effective approach to input variable selection for preliminary cost estimation of construction projects. Advances in Civil Engineering, Article ID 4092549. https://doi.org/10.1155/2019/4092549

Morovatdar, R., Aghaie, A., Roghanian, A., \& AslHaddad, A. (2013). An algorithm to obtain possibly critical paths in imprecise project networks. Iranian Journal of Operations Research, 4, 39-54.
Pawan, P., \& Lorterapong, P. (2016). A fuzzy-based integrated framework for assessing time contingency in construction projects. Journal of Construction Engineering and Management, 142(3), 04015083.

https://doi.org/10.1061/(ASCE)CO.1943-7862.0001073

Phama, H., Luub, T. V., Kimc, S. Y. \& Viend, D. T. (2020). Assessing the impact of cost overrun causes in transmission lines construction projects. KSCE Journal of Civil Engineering, 24(4), 1029-1036. https://doi.org/10.1007/s12205-020-1391-5

Plebankiewicz, E. (2018). Model of predicting cost overrun in construction projects. Sustainability, 10(12), 4387.

https://doi.org/10.3390/su10124387

Plebankiewicz, E., \& Karcińska, P. (2016). Creating a construction schedule specifying fuzzy norms and the number of workers. Archives of Civil Engineering, 62(3), 149-166. https://doi.org/10.1515/ace-2015-0089

Plebankiewicz, E. \& Wieczorek, D. (2016). Rozmyta ocena ryzyka w cyklu życia obiektów budowlanych. Materialy Budowlane, 6, 59-61 (in Polish). https://doi.org/10.15199/33.2016.06.25

Plebankiewicz, E., \& Wieczorek, D. (2018). Multidimensional sensitivity study of the fuzzy risk assessment module in the life cycle of building objects. Open Engineering, 8(1), 490499. https://doi.org/10.1515/eng-2018-0059

Plebankiewicz, E. \& Wieczorek, D. (2020). Adaptation of a cost overrun risk prediction model to the type of construction facility. Symmetry, 12, 1739.

https://doi.org/10.3390/sym12101739

Plebankiewicz, E., Zima, K. \& Wieczorek, D. (2015). Identification of risk factors in the life cycle cost of a building. In D. Skorupka (Ed.), Scientific problems in project management (pp. 153-165). Wydawnictwo Wyższej Szkoły Oficerskiej Wojsk Lądowych imienia generała Tadeusza Kościuszki.

Plebankiewicz, E., Zima, K., \& Wieczorek. D. (2019). Original model for estimating the whole life costs of buildings and its verification. Archives of Civil Engineering, 65(2), 163-179. https://doi.org/10.2478/ace-2019-0026

Plebankiewicz, E., Meszek, W., Zima, K., \& Wieczorek, D. (2020). Probabilistic and fuzzy approaches for estimating the life cycle costs of buildings under conditions of exposure to risk. Sustainability, 12(1), 226. https://doi.org/10.3390/su12010226

Princy, S., \& Dhenakaran, S. (2016). Comparison of triangular and trapezoidal fuzzy membership function. Journal of Computer Science and Engineering, 2(8), 46-51.

Ramli, N., \& Mohamad, D. (2010). Fuzzy Jaccard with degree of optimism ranking index based on function principle approach. Majlesi Journal of Electrical Engineering, 4(4), 9-15.

Salah, A., \& Moselhi, O. (2015). Contingency modelling for construction projects using fuzzy-set theory. Engineering, Construction and Architectural Management, 22(2), 214-241. https://doi.org/10.1108/ECAM-03-2014-0039

San Cristobal, J. (2013). Critical path definition using multi criteria decision making: the PROMETHEE method. Journal of Management in Engineering, 29(2), 158-163. https://doi.org/10.1061/(ASCE)ME.1943-5479.0000135

Seker, S., \& Zavadskas, E. K. (2017). Application of fuzzy DEMATEL method for analyzing occupational risks on construction sites. Sustainability, 9(11), 2083. https://doi.org/10.3390/su9112083

Sekocenbud. (2020a). Biuletyn cen regionalnych (BCR) [Regional prices bulletin, quarters I-III] (in Polish).

Sekocenbud. (2020b). Zagregowane wskaźniki waloryzacyjnoprognostyczne I-III kw. [Aggregate indexing and forecasting indicators, quarters I-III] (in Polish). 
Shaheen, A. A., Fayek, A. R., \& AbouRizk, S. M. (2007). Fuzzy numbers in cost range estimating. Journal of Construction Engineering and Management, 133(4), 325-334. https://doi.org/10.1061/(ASCE)0733-9364(2007)133:4(325)

Shakeela, S., \& Gansean, K. (2011). A simple approach to fuzzy critical path analysis in project networks. International Journal of Scientific and Engineering Research, 2(12), 1-11.

Sharma, S., \& Goyal, P. K. (2019). Fuzzy assessment of the risk factors causing cost overrun in construction industry. Evolutionary Intelligence. https://doi.org/10.1007/s12065-019-00214-9

Soltani, A, \& Haji, R. (2007). A project scheduling method based on fuzzy theory. Journal of Industrial and Systems Engineering, 1, 70-80.

Taylan, O., Bafail, A. O., Abdulaal, R. M., \& Kabli, M. R. (2014). Construction projects selection and risk assessment by fuzzy AHP and fuzzy TOPSIS methodologies. Applied Soft Computing, 17, 105-116. https://doi.org/10.1016/j.asoc.2014.01.003

Wieczorek, D. (2018). Fuzzy risk assessment in the life cycle of building object - selection of the right defuzzification method. In AIP Conference Proceedings. AIP Publishing. https://doi.org/10.1063/1.5043866

Wang, R. C., \& Liang, T. F. (2004). Project management decisions with multiple fuzzy goals. Construction Management and Economics, 22(10), 1047-1056. https://doi.org/10.1080/0144619042000241453

Yu, W.-D., \& Skibniewski, M. J. (2010). Integrating neurofuzzy system with conceptual cost estimation to discover cost related knowledge from residential construction projects. Journal of Computing in Civil Engineering, 24(1), 35-44. https://doi.org/10.1061/(ASCE)0887-3801(2010)24:1(35)

Zadeh, L. A. (1965). Fuzzy sets. Information and Control, 8, 338 353. https://doi.org/10.1016/S0019-9958(65)90241-X

Zavadskas, E. K., Antucheviciene, J., Turskis, Z., \& Adeli, H. (2016). Hybrid multiple-criteria decision-making methods: A review of applications in engineering. Scientia Iranica, 23, 1-20. https://doi.org/10.24200/sci.2016.2093

Zavadskas, E. K., Antucheviciene, J., Vilutiene, T., \& Adeli, H. (2018). Sustainable decision-making in civil engineering, construction and building technology. Sustainability, 10(1), 14. https://doi.org/10.3390/su10010014

Zhang, N., \& Wei, G. (2013). Extension of VIKOR method for decision making problem based on hesitant fuzzy set. Applied Mathematical Modelling, 37(7), 4938-4947. https://doi.org/10.1016/j.apm.2012.10.002

Zheng, D. X. M., \& Ng. T. (2005). Stochastic time-cost optimization model incorporating fuzzy sets theory and non-replacement. Journal of Construction Engineering and Management, 131(2), 176-186. https://doi.org/10.1061/(ASCE)0733-9364(2005)131:2(176)

Zima, K. (2015). The use of fuzzy case-based reasoning in estimating costs in the early phase of the construction project. In AIP Conference Proceedings. https://doi.org/10.1063/1.4912842

Zolfaghari, S., \& Mousavi, S. M. (2018). Construction-project risk assessment by a new decision model based on De-Novo multi-approaches analysis and hesitant fuzzy sets under uncertainty. Journal of Intelligent \& Fuzzy Systems, 35, 639-649. https://doi.org/10.3233/JIFS-162013 